\title{
Efficacy of Plug Treatment for Complex Anorectal Fistulae: Long-term Danish Results
}

\author{
Melina Svraka Hansen, Monica Linda Kjær, Jens Andersen \\ Copenhagen University Hospital, Hvidovre, Gastro Unit, Centre for Surgical Research, Hvidovre, Denmark
}

Purpose: Bioprosthetic plugs are appealing, allow simple, repeatable applications, preserve sphincter integrity, minimize patient discomfort, and allow subsequent surgical options when needed. However, success rates vary widely. This study assessed the healing rate in our department when both the Cook-Surgisis and the Gore fistula plugs were used and the long-term effectiveness of using anal plugs for managing anal fistulae.

Methods: A chart review was performed for patients who had undergone plug insertion between January 2008 and December 2015 at Copenhagen University Hospital, Hvidovre. Data were collected through a prospectively collected database. Plugs were inserted according to guidance provided by 2 experienced surgeons. Long-term results were determined by clinical visits 3,6 , and 12 months after surgery and once yearly thereafter.

Results: From 2008 to 2015, 36 fistula plugs were inserted. During the follow-up period with a median duration of 18 months (range, $7-60$ months), the fistulae of $52.8 \%$ of the patients healed. The plug failure rate was $44.4 \%$, and the fistula recurrence rate was $26.3 \%$. The median time to recurrence was 12 months. The overall success rate for plug treatment in our department was $39 \%$ when adjusted for recurrence.

Conclusion: The use of bioprosthetic plugs to treat patients with complex anal fistulae seems to be a safe, viable option for complex fistula repair when other surgical attempts have failed. However, it should not be the treatment of choice. Further prospective randomized studies with a sufficient sample-size and standardized measurements are necessary to evaluate the efficacy of fistula plugs fully.

Keywords: Anorectal fistula; Fistula plugs; Bioprosthetic plugs; Plug efficacy, Cook-Surgisis plug; Gore plug

\section{INTRODUCTION}

The treatment of an anal fistula depends on the complexity and the location of the fistula tract. A fistula can be distinguished as a low or high anal fistula. Furthermore, a fistula can be categorized as either simple or complex. A simple fistula is usually a low fistula without secondary tracts. A complex fistula includes a high primary fistula tract, a low fistula in patients with pre-existing in-

Received: March 5, 2018 - Accepted: July 14, 2018

Correspondence to: Melina Svraka Hansen, M.D.

Copenhagen University Hospital, Hvidovre, Gastro Unit, Centre for Surgical Research, Kettegård Alle 30, Hvidovre 2650, Denmark

Tel: +45-28-30-47-57

E-mail:melinasvraka@gmail.com

ORCID code: https://orcid.org/0000-0002-1694-6250

(C) 2019 The Korean Society of Coloproctology

This is an open-access article distributed under the terms of the Creative Commons Attribution NonCommercial License (http://creativecommons.org/licenses/by-nc/4.0) which permits unrestricted noncommercial use, distribution, and reproduction in any medium, provided the original work is properly cited. continence, secondary tracts, a horseshoe fistula, or a fistula associated with inflammatory bowel disease (IBD) and malignancy. The primary goal of fistula treatment is the healing of fistula openings and any associated tracts without any change in continence [1]. The task for the surgeon is to assess whether the fistula is simple or complex so that the most appropriate surgical technique can be used.

The management of a complex fistula is difficult due to the high risk of a division of the anal sphincter and possible disturbances in continence. Over recent years, several techniques and materials have been used to treat complex anal fistulae, including the draining seton, advancement flap formation, ligation of the intersphincteric fistula tract (LIFT), plugs, and recently video-assisted anal fistula treatment (VAAFT).

The use of a fistula plug was first described in 2006 [2]. Treating a complex fistula with a bioprosthetic plug is appealing because it allows simple and repeatable application, preserves sphincter integrity, minimizes patient discomfort, and allows subsequent sur- 
gical options if needed. However, success rates vary widely. The experiences of various surgeons with fistula repair by using plugs have shown both favorable and disappointing results. Early results were promising, showing a success rate of up to over $80 \%$ with the use of the Cook-Surgisis anal fistula plug [2-4]. Subsequent reports were not able to replicate that high success rate [5-7]. Thus, the aim of this study was to assess the healing rate in our department when using both the Cook-Surgisis and the Gore fistula plugs and to evaluate the long-term effectiveness of using an anal plug to manage high anal fistulae.

\section{METHODS}

The study was conducted in accordance with the guidelines of the Danish Institutional Review Board, and no additional written approval was required [8]. A chart review was performed for all patients (36 patients) who had undergone plug (Cook-Surgisis or Gore) insertion between January 2008 and December 2015 at the Copenhagen University Hospital, Hvidovre. Plugs were routinely used in all patients with complex fistulae as the treatment of choice during the study period to avoid selection bias. Data were collected through a prospectively collected database. Medical records and surgical reports were reviewed, and data regarding age, sex, fistula anatomy and etiology (cryptoglandular vs. IBD), diagnostic modality (clinical evaluation vs. magnetic resonance imaging $[\mathrm{MRI}])$, history of previous repair, comorbidities and fistula recurrence were collected.

All patients provided informed consent. Patients were examined before plug insertion by specialists in fistula diseases, and tract preparation with a ubiquitous seton was performed prior to plug insertion. The preoperative protocol for all patients included bowel preparation with a single colon cleansing with the liquid klysma and a single dose of prophylactic broad-spectrum intravenous antibiotics administrated preoperatively. All procedures were done under general anesthetics in a lithotomic position, and patients were discharged the same day and given a 5-day analgesia treatment. Patients were reviewed in the outpatient department for a period of 3 months following surgery. Healing was solely determined by clinical evaluation using an anoscope by the same surgeon who did the procedure. Clinical healing was defined as the absence of drainage, with no evidence of an internal or an external opening. Long-term results were determined based on data obtained during clinical visits 3, 6, and 12 months after surgery and once yearly thereafter. Patients' symptoms regarding secretion, pain, and continence were routinely recorded at the visits. Even when healing was observed, patients were not discharged.

The plug procedure was performed by 2 separate surgeons, both of whom were experienced in fistula surgery. Each primary opening was occluded by using ether the Cook-Surgisis anal fistula plug or the Gore fistula plug, and the plugs were inserted according to the following manufacturers' guidelines $[9,10]$.

The Cook-Surgisis fistula plug is a bioprosthetic plug composed of porcine intestinal submucosa [9]. The plug is submerged in sterile hydration fluid prior to insertion, and a suitable suture is applied on the tail of the plug. The fistula tract is cleaned with hydrogen peroxide using a catheter. The suture from the tail is attached to the seton at the internal opening, and the tie is drawn into the internal opening through the fistula tract (Fig. 1A). The plug is subsequently trimmed at the level of the bowel wall and sutured with resorbable sutures (Fig. 1B, C).

The GORE BIO-A fistula plug is a tailored, bio-absorbable device intended to occupy the fistula tract until the bio-absorbable nature of the material allows the body to fill the defect with native tissue. The device is comprised of a disk attached to multiple tubes. The plug has a porous fibrous structure composed solely of a synthetic bio-absorbable poly (glycolide:trimethylene carbonate) copolymer [10]. The suture attached to the distal end of the plug is drawn to the internal opening of the fistula tract through the fistula tract. When the suture is visible at the external opening, the GORE BIO-A fistula plug is inserted into the defect until a slight resistance is felt, after which the device disk is seated at the internal opening ensuring that the disk lies flat and is well opposed to the rectal mucosa at the internal opening of the fistula tract. After the device is properly positioned, it is fixated with a suitable ab-


Fig. 1. Surgical procedure: plug insertion (A), plug fixation (B), and plug in situ at the end (C). 
sorbable suture, securing the disk to the adjacent tissue by obtaining adequate bites of rectal wall to prevent device migration and minimize the potential for leakage of bowel contents into the fistula tract.

\section{RESULTS}

From 2008 to 2015, a total of 36 fistula plugs were inserted in 36 patients at the Copenhagen University Hospital, Hvidovre. Patients' demographics and outcomes are summarized in Table 1. Twenty-five of the 36 patients (69.4\%) were women, and 11 (30.6\%) were men. The median age was 43.7 years (range, 18-77 years). A history of IBD was present in 11 of the 36 patients (30.6\%), and the fistulae in the remaining 25 patients (69.4\%) had a cryptoglandular origin. The course of the fistula tract and location were first determined clinically for all patients, and $23 \mathrm{pa}-$ tients (63.9\%) had an additional MRI. Most of the anal fistulae, 32 of $36(88.9 \%)$, were high transsphincteric fistulae, and 4 (11.1\%) were suprasphincteric. All the fistula tracts were straight, single and unbranching tracts without intersphincteric complexity. For all patients, the types of fistulae included posterior ( 20 of 36 , $55.6 \%$ ), anterior ( 10 of $36,27.8 \%$ ), and anovaginal (6 of $3616.7 \%$ ) fistulae. The median follow-up was 18 months (range, 7-60 months). One patient was lost to follow-up after plug insertion

Table 1. Demographics and outcome details

\begin{tabular}{lrrr}
\hline Variable & No. (\%) & $\begin{array}{c}\text { Healing, } \\
\mathrm{n}(\%)\end{array}$ & $\begin{array}{c}\text { Recurrence, } \\
\mathrm{n}(\%)\end{array}$ \\
\hline Sex & & & \\
$\quad$ Female & $25 / 36(69.4)$ & $12 / 25(48.0)$ & $3 / 12(25.0)$ \\
$\quad$ Male & $11 / 36(30.6)$ & $7 / 11(63.6)$ & $2 / 7(28.6)$ \\
Fistula origin & & & \\
$\quad$ Cryptoglandular & $25 / 36(69.4)$ & $15 / 25(60.0)$ & $5 / 15(33.3)$ \\
Inflammatory bowel disease & $11 / 36(30.6)$ & $4 / 11(36.4)$ & $0 / 4(0)$ \\
$\quad$ Ulcerative colitis & $7 / 36(19.4)$ & $3 / 7(42.9)$ & $0 / 3(0)$ \\
$\quad$ Crohn disease & $4 / 36(11.1)$ & $1 / 4(25.0)$ & $0 / 1(0)$ \\
Type of fistula & & & \\
$\quad$ First time & $26 / 36(72.2)$ & $12 / 26(46.2)$ & $3 / 12(25.0)$ \\
\hline Chronic & $10 / 36(27.8)$ & $7 / 10(70.0)$ & $2 / 7(28.6)$ \\
\hline Location & & & \\
$\quad$ Anterior & $10 / 36(27.8)$ & $7 / 10(70.0)$ & $2 / 7(28.6)$ \\
\hline Posterior & $20 / 36(55.6)$ & $11 / 20(55.0)$ & $3 / 11(27.3)$ \\
$\quad$ Vaginal & $6 / 36(16.7)$ & $1 / 6(16.7)$ & $0 / 1(0)$ \\
Transsphincteric & $32 / 36(88.9)$ & $17 / 32(53.1)$ & $4 / 17(23.5)$ \\
\hline Suprasphincteric & $4 / 36(11.1)$ & $2 / 4(50.0)$ & $1 / 2(50.0)$ \\
\hline Plug type & & & \\
$\quad$ Cook-Surgisis & $26 / 36(72.2)$ & $15 / 26(57.7)$ & $3 / 15(20.0)$ \\
$\quad$ Gore & $10 / 36(27.8)$ & $4 / 10(40.0)$ & $2 / 4(50.0)$ \\
\hline
\end{tabular}

due to immigration but was included in the intention-to-treat analyses. Almost all patients (34 of 36, 94.4\%) had a draining ubiquitous loose seton inserted before the anal fistula plug procedure, which was in place for a median of 5 months. Of those 34 patients with draining seton, 6 patients had undergone previous attempts at a cure, 4 had tried partial incision of the fistula, 1 had had a previous attempt with a plug, and 1 patient had had 3 attempts, 1 each with excision, a plug, and VAAFT. Only 2 of the 36 patients had the plug directly inserted. The Cook-Surgisis plugs were inserted in 26 of the 36 patients (72.2\%), and the Gore plug was used in 10 (27.8\%). Before 2010, all patients were treated with the Cook-Surgisis plug. The Gore plug was first introduced in November 2010 in our department. After that time, the plugs were equally distributed, 10 patients were treated with each plug.

During the follow-up period, the fistulae in 19 of the 36 patients (52.8\%) healed: 15 of 26 patients (57.7\%) in the Cook-Surgisis group and 4 of 10 patients (40.0\%) in the Gore group. Calculated from the date of surgery, the fistulae in 11 of the 36 patients (30.6\%) had closed with no discomfort or secretion reported within 3 months. During the period from 3 to 6 months, another 3 fistulae for a total of 14 of the 36 patients (38.9\%) had closed, and during the period from 6 to 9 months, another 4 fistulae for a total of 18 of the 36 patients (50.0\%) had closed. One patient experienced delayed closure within the period from 9 to 17 months. Plug failure occurred in 16 of the 36 patients (44.4\%). Of the patients with plug failure, 2 (5.6\%) had plug dislodgement, 1 in each group, and 14 (38.9\%) had continuous discomfort and secretion and no signs of healing upon control in the outpatient department. None had sepsis. The fistula recurred in 5 of the 19 patients (26.3\%) that had experienced complete closure. Most fistulae recurred within the first year, although one late recurrence occurred 16 months after healing. The median time to recurrence was 12 months. The overall success rate for plug treatment in our department was 39\% (14 of 36 patients) when adjusted for recurrence.

All 5 patients who suffered a recurrence after complete closure had a fistula of cryptoglandular origin: 3 recurrences among the 12 patients $(25.0 \%)$ with chronic fistulae (fistulae with former attempts at a cure), and 2 among the 7 patients (28.6\%) who had experienced a fistula for the first time. Of the 5 patients with recurrence, 3 subsequently underwent a VAAFT procedure, and 2 had reinsertion of a loose seton. None had reinsertion of a plug.

The statistical analysis with the chi-square test showed no statistical correlation with age, sex, fistula anatomy and etiology, comorbidity, previous operation, plug type, and treatment failure $(\mathrm{P}>$ 0.05). No mortality, major complications, or postoperative incontinence was observed.

\section{DISCUSSION}

The Cook-Surgisis plug has been in use for several years, and so far, many data show a variable result. Two systematic reviews of the Cook-Surgisis anal fistula plug reported success rates ranging 
from $20 \%$ to $86 \%$ and $24 \%$ to $94 \%$, respectively $[7,11]$. The Gore fistula plug is purported to be an improvement in design over the Cook-Surgisis plug because it has an absorbable synthetic material. With an expanded disc at one end and several tails, the Gore plug can be fixated more easily and is less likely to migrate or become dislodged because the disc is anchored to the sphincter and buried under the mucosal flap. However, the data on the Gore plug is limited. The latest systematic review that included the use of the Gore fistula plug reported a healing rate from $15.8 \%$ to $72.7 \%$ [12]. According to a systematic review of fistulae associated with Crohn disease, the healing rate for fistulae of cryptoglandular origin reached $58.3 \%$, with a recurrence rate of $13.6 \%$ [13].

Only one study has compared the outcomes between the use of a Cook-Surgisis fistula plug and a Gore fistula plug [14]. In that study, the Gore plug was found to be more favorable, having a healing rate of $54.4 \%$ compared to $12.5 \%$ in the Cook-Surgisis group. However, the results should be interpreted carefully due to the small sample size and short follow-up. In our study, which also has a small sample size, we found the overall healing rate to be $39 \%$, with no difference in healing between the insertion of a Cook-Surgisis plug and the insertion of a Gore plug. In both groups, healing occurred in half of the patients. Many studies have claimed, that failure with the Cook plug is due to plug dislodgement, showing an extrusion rate between $4 \%-41 \%[3,6,7$, 15]. In our study, only 2 patients suffered plug dislodgement, and although the Gore design seemed more resistant to plug dislodgement, failure rates remained high; we unable to reproduce the high success rates reported earlier in the literature.

That most fistula failures occur within the first 3 months after treatment is well known $[3,16]$. Nevertheless, a significant proportion is expected to occur after that time, and 1 year is generally the length of follow-up needed before final results are known. Early results from 2007 were promising, showing a recurrence of $12 \%$ [16]; however, that study had a low follow-up period of only 6 months. The same author showed a recurrence rate of only $6 \%$ in a later study with a longer follow-up period (median, 12 months) [3]. A recent retrospective study with a long follow-up of 59 weeks reported recurrence in $86.7 \%$ of the patients, a very high recurrence rate [17]. In the literature, generally not much data on the recurrence rate after treatment with plugs are available, which is the reason firm conclusions regarding the efficacy of plugs should be interpreted carefully.

Possible explanations for the inconsistent data in the literature include technical problems with plug fixation, difference in patient selection, difference in clinical evaluation, and lack of postprocedure MRI. The current study, which has a very long follow-up period (median, 18 months), found a recurrence rate of $26.3 \%$ within a median time of 12 months from clinically evaluated healing. Even though the failure of the plug does not preclude the later use of other treatment strategies, the evidence base is of poor quality, lacking standardized measurements and sufficient follow-up.

Transanal advancement flap therapy (TAFR) and LIFT are alter- nate well-known sphincter-preserving procedures for the treatment of high anal fistulae. LIFT has gained popularity since 2008 mainly due to its having initially high success rates and its being a relative simple procedure. A systematic review of 35 publications from 1978 to 2008 report success rates from $24 \%$ to $100 \%$, and an average of $81 \%$ [18]. No studies compare LIFT to plug treatment, but a recent randomized study showed higher healing with LIFT and additional plugs rather than LIFT alone [17]. Furthermore, no incontinence or recurrence was reported within the follow-up period of 6 months [19].

Two randomized trials have compared TAFR to plug treatment $[20,21]$. They both show higher healing and lower recurrence using the TAFR technique. The first randomized trial by Ortiz et al. [20] was prematurely terminated due to the high recurrence rate of $80 \%$ in the plug group. Van Koperen et al. [21] found a recurrence of $71 \%$ in the plug group and $52 \%$ in the advancement flap group, which were not significantly different. In addition, no statistically significant differences in postoperative pain, pre- and postoperative incontinence score, soiling, and quality of life that favored the plug as an initial treatment option due to its minimally invasive nature were found [21].

The recurrence rate of fistulae treated with only a loose seton is reported to be $0 \%-19.5 \%$ [22-24] with minor flatus incontinence and major stool incontinence reported in $0 \%-8 \%$ and $0 \%-7.5 \%$ of the cases, respectively [22-25]. In our study, all patient, except 2, were treated with a loose seton prior to the insertion of the plug to ensure absence of active infection. So far, the loose seton has been a safe treatment for complex fistulae and has often been used as a bridge to definitive surgery by ensuring drainage and marking the fistula tract [1]. It has also been a treatment for chronic fistulae in patients not suited for further treatment. The disadvantage is, however, the long follow-up period required, as the healing process is slow. Pretreatment with a seton prior to definitive surgery is a common practice, although the evidence base is controversial. According to the literature, no evidence exists for improved outcome prior to placement of endorectal advancement flap, LIFT procedure or plug insertion $[2,18,26]$.

Some studies have addressed the localization of the fistula opening having an influence on healing. A multicenter study showed that anterior fistulae were less likely to heal compared to fistulae in other locations. A success rate of $12 \%$ was observed for patients with an anterior fistula compared to $32 \%$ for those with posterior tracks [5]. Our study could not reproduce these data, and we had a greater healing rate for anterior fistulae, with a success rate of $70 \%$ for the anterior fistulae versus $55 \%$ for the posterior fistulae. Although we could not show any statistical differences between the success and the failure groups, probably due to the sample size, the healing rate in fistulae associated with Crohn disease and vaginal fistulae were low, $25 \%$ and $16.7 \%$, respectively, whereas cryptoglandular fistulae were more likely to heal, making them a better choice for plug treatment. Treatment of transsphincteric fistulae with a plug also seems to have better potential for healing 
than treatment of suprasphincteric fistulae with a plug. These findings are in accordance with results in a retrospective German multicenter study [27].

Surprisingly, the healing rate for chronic fistulae (fistulae previously undergoing closure attempts) was 70\% in the current study, and the recurrence rate in this subgroup was not higher compared to the recurrence rate for first-time fistulae, as might have been expected. However, the reader should not draw any firm conclusion due to the small sample size. This only highlights the complexity of treatment of anal fistulae as patients often require more than one closure attempt.

No consensus exists as to whether or not MRI is required before fistula surgery and in the evaluation of healing. However, good evidence exists that MRI detects complexity that clinical evaluation has missed, leading to a reduced recurrence rate. In our case, only half of the patients had an additional MRI done before surgery, and the healing of the fistulae was exclusively based on clinical evaluation. This study, therefore, has some drawbacks. As generally in the literature, our study lacks standardized measurements due to the fact that it is based on retrospectively collected data. Furthermore, our patient population is heterogeneous and too small to draw firm conclusions. All these confounders can lead to an overestimate of the healing rate and an underestimate of the recurrence rate and can explain the conflicting results on plug treatment. The power in the current study lies in its follow-up period, exceeding 1.5 years, which is longer than most of the followup periods in other studies. Due to the long follow-up, a more reliable measurement of the overall efficacy can be estimated, as it is adjusted for recurrence.

In conclusion, using bioprosthetic plugs in the treatment of complex anal fistulae seems to be safe; the plugs are easy to apply, minimally invasive and continence preserving, making their use a viable option for complex fistula repair when other surgical attempts have failed. However, in the long run, plugs should not be recommended as the treatment of choice due to the increased failure rate. Further prospective randomized studies of sufficient sample size and with standardized measurements of healing are necessary if the efficacy of using fistula plugs to treat fistulae is to be fully evaluated.

\section{CONFLICT OF INTEREST}

No potential conflict of interest relevant to this article was reported.

\section{REFERENCES}

1. Lundby L, Hagen K, Christensen P, Buntzen S, Thorlacius-Ussing $\mathrm{O}$, Andersen J, et al. Treatment of non-IBD anal fistula. Dan Med J 2015;62.

2. Champagne BJ, O'Connor LM, Ferguson M, Orangio GR, Schertzer ME, Armstrong DN. Efficacy of anal fistula plug in clo- sure of cryptoglandular fistulas: long-term follow-up. Dis Colon Rectum 2006;49:1817-21.

3. Ellis CN, Rostas JW, Greiner FG. Long-term outcomes with the use of bioprosthetic plugs for the management of complex anal fistulas. Dis Colon Rectum 2010;53:798-802.

4. Zubaidi A, Al-Obeed O. Anal fistula plug in high fistula-in-ano: an early Saudi experience. Dis Colon Rectum 2009;52:1584-8.

5. Blom J, Husberg-Sellberg B, Lindelius A, Gustafsson UM, Carlens $\mathrm{S}$, Oppelstrup $\mathrm{H}$, et al. Results of collagen plug occlusion of anal fistula: a multicentre study of 126 patients. Colorectal Dis 2014; 16:626-30.

6. McGee MF, Champagne BJ, Stulberg JJ, Reynolds H, Marderstein E, Delaney CP. Tract length predicts successful closure with anal fistula plug in cryptoglandular fistulas. Dis Colon Rectum 2010;53: 1116-20.

7. Garg P, Song J, Bhatia A, Kalia H, Menon GR. The efficacy of anal fistula plug in fistula-in-ano: a systematic review. Colorectal Dis 2010;12:965-70.

8. Forsøgstyper uden anmeldelsespligt [Internet]. Copenhagen (Denmark): The Danish National Committee on Health Research Ethics; [cited 2018 Mar 9]. Available from: https://komite.regionsyddanmark.dk/wm428123.

9. Biodesign ${ }^{\circledR}$ anal fistula plug instructions for use [Internet]. West Lafayette (IN): Cook Biotech; [cited 2017 Apr 11]. Available from: https://www.cookmedical.com/data/IFU_PDF/FP0037-03I.PDF.

10. $\mathrm{GORE}^{\circledR} \mathrm{BIO}-\mathrm{A}^{\circledR}$ Fistula Plug | Gore Medical [Internet] Flagstaff (AZ): W.L. Gore \& Associates, Inc.; [cited 2019 Jan 25]; Available from: https://www.goremedical.com/products/bioafistulaplug.

11. O’Riordan JM, Datta I, Johnston C, Baxter NN. A systematic review of the anal fistula plug for patients with Crohn's and nonCrohn's related fistula-in-ano. Dis Colon Rectum 2012;55:351-8.

12. Narang SK, Jones C, Alam NN, Daniels IR, Smart NJ. Delayed absorbable synthetic plug $\left(\mathrm{GORE}^{\circledR} \mathrm{BIO}-\mathrm{A}^{\circledR}\right)$ for the treatment of fistula-in-ano: a systematic review. Colorectal Dis 2016;18:37-44.

13. Nasseri Y, Cassella L, Berns M, Zaghiyan K, Cohen J. The anal fistula plug in Crohn's disease patients with fistula-in-ano: a systematic review. Colorectal Dis 2016;18:351-6.

14. Buchberg B, Masoomi H, Choi J, Bergman H, Mills S, Stamos MJ. A tale of two (anal fistula) plugs: is there a difference in shortterm outcomes? Am Surg 2010;76:1150-3.

15. Schwandner T, Roblick MH, Kierer W, Brom A, Padberg W, Hirschburger M. Surgical treatment of complex anal fistulas with the anal fistula plug: a prospective, multicenter study. Dis Colon Rectum 2009;52:1578-83.

16. Ellis CN. Bioprosthetic plugs for complex anal fistulas: an early experience. J Surg Educ 2007;64:36-40.

17. Tan KK, Kaur G, Byrne CM, Young CJ, Wright C, Solomon MJ. Long-term outcome of the anal fistula plug for anal fistula of cryptoglandular origin. Colorectal Dis 2013;15:1510-4.

18. Hong KD, Kang S, Kalaskar S, Wexner SD. Ligation of intersphincteric fistula tract (LIFT) to treat anal fistula: systematic review and meta-analysis. Tech Coloproctol 2014;18:685-91. 
19. Han JG, Wang ZJ, Zheng Y, Chen CW, Wang XQ, Che XM, et al. Ligation of intersphincteric fistula tract vs ligation of the intersphincteric fistula tract plus a bioprosthetic anal fistula plug procedure in patients with transsphincteric anal fistula: early results of a multicenter prospective randomized trial. Ann Surg 2016; 264:917-22.

20. Ortiz H, Marzo J, Ciga MA, Oteiza F, Armendáriz P, de Miguel M. Randomized clinical trial of anal fistula plug versus endorectal advancement flap for the treatment of high cryptoglandular fistula in ano. Br J Surg 2009;96:608-12.

21. van Koperen PJ, Bemelman WA, Gerhards MF, Janssen LW, van Tets WF, van Dalsen AD, et al. The anal fistula plug treatment compared with the mucosal advancement flap for cryptoglandular high transsphincteric perianal fistula: a double-blinded multicenter randomized trial. Dis Colon Rectum 2011;54:387-93.

22. Eitan A, Koliada M, Bickel A. The use of the loose seton technique as a definitive treatment for recurrent and persistent high trans-sphincteric anal fistulas: a long-term outcome. J Gastroin- test Surg 2009;13:1116-9.

23. Tokunaga Y, Sasaki H, Saito T. Clinical role of a modified seton technique for the treatment of trans-sphincteric and suprasphincteric anal fistulas. Surg Today 2013;43:245-8.

24. Subhas G, Gupta A, Balaraman S, Mittal VK, Pearlman R. Noncutting setons for progressive migration of complex fistula tracts: a new spin on an old technique. Int J Colorectal Dis 2011;26:793-8.

25. Mancilla GP, M GC, S GU, L SN, P MEM, R FB, et al. Modified loose-seton technique for the treatment of complex anal fistulas. Colorectal Dis 2010;12:e310-3.

26. van Onkelen RS, Gosselink MP, Schouten WR. Is it possible to improve the outcome of transanal advancement flap repair for high transsphincteric fistulas by additional ligation of the intersphincteric fistula tract? Dis Colon Rectum 2012;55:163-6.

27. Ommer A, Herold A, Joos A, Schmidt C, Weyand G, Bussen D. Gore BioA Fistula Plug in the treatment of high anal fistulas--initial results from a German multicenter-study. Ger Med Sci 2012; 10:Doc13. 